\title{
Field studies on the soil loss reduction effectiveness of three biodegradable geotextiles
}

\author{
Flavia Tauro, ${ }^{1}$ Paolo Cornelini, ${ }^{2}$ Salvatore Grimaldi, ${ }^{1,3}$ Andrea Petroselli ${ }^{4}$ \\ ${ }^{1}$ Department for Innovation in Biological, Agro-food and Forest systems, University of Tuscia, Viterbo, Italy; \\ ${ }^{2}$ Department of Agriculture and Forest Sciences, University of Tuscia, Viterbo, Italy; ${ }^{3}$ Department of Mechanical and \\ Aerospace Engineering, New York University Tandon School of Engineering, Brooklyn, NY, USA; ${ }^{4}$ Department of \\ Economics, Engineering, Society and Business Organisation, University of Tuscia, Viterbo, Italy
}

\begin{abstract}
Biodegradable geotextiles have the potential to significantly reduce soil loss and ensure slope stability in areas at risk. Here, we focus on three biodegradable textiles (namely, jute net, jute mat, and wool mat), and study their response in terms of soil loss to diverse precipitation events (average rainfall intensity from 3.7 $\mathrm{mmh}^{-1}$ to $70 \mathrm{mmh}^{-1}$ and duration from $0.5 \mathrm{~h}$ to $11.6 \mathrm{~h}$ ). Experiments are conducted in an ad hoc developed outdoor steep slope (more than 60\%). Soil loss reduction from the treatments is found to be very remarkable (up to $98 \%$ ), thus supporting the potential of natural materials for soil conservation. Also, experimental findings confirm that the maximum intensity of rainfall events plays an important role in driving soil erosion.
\end{abstract}

\section{Introduction}

Soil erosion is a significant threat for food and environment security. In fact, erosion depletes the soil of water and nutrients that are of paramount importance for agricultural productivity and for preserving biodiversity. With the rapid economic development

Correspondence: Andrea Petroselli, Department of Economics, Engineering, Society and Business Organisation, University of Tuscia, Viterbo 01100, Italy.

E-mail: petro@unitus.it

Key words: Soil erosion; geotextiles; bioengineering.

Acknowledgements: the Authors wish to thank JutaTex srl for providing the geotextiles. Paolo Ciorba, Giuliano Cipollari, Giordano Fioramanti, Angelo Orlando, and Roberto Rapiti are greatly acknowledged for developing the experimental setup and for help with the experiments.

Received for publication: 12 October 2017.

Accepted for publication: 2 December 2017

(C) Copyright F. Tauro et al., 2018

Licensee PAGEPress, Italy

Journal of Agricultural Engineering 2018; XLIX:799

doi:10.4081/jae.2018.799

This article is distributed under the terms of the Creative Commons Attribution Noncommercial License (by-nc 4.0) which permits any noncommercial use, distribution, and reproduction in any medium, provided the original author(s) and source are credited. and population growth, soil loss has been constantly accelerated by extensive road networks and infrastructure advancement, especially in developing countries (Luo et al., 2013). Slope excavations result in large bare soil areas, which are highly vulnerable to erosion. In such steep slopes, complex soil erosion and groundwater processes challenge earth stability, with negative impacts on human activities. To this end, past efforts have traditionally entailed the construction of physical structures, such as bench terraces, which may be labour intensive and expensive (Vishnudas et al., 2012). More recently, soil conservation techniques have entailed the use of geotextiles for runoff and soil loss reduction (Bresci and Preti, 2010). This approach has proved generally more effective than soil management techniques (Guerra et al., 2015), even if geotextile-based soil conservation is still relatively underresearched.

The use of geotextiles as flood protection techniques is documented since the thirteenth century (Evette et al., 2009). These materials are defined as permeable textiles used in conjunction with soil, foundation, rock, earth or any geotechnical engineeringrelated material (John, 1987), and have been used for soil erosion control, slope stabilisation, and vegetation management, among others (Bhattacharyya et al., 2010). Geotextile salient features are their percentage cover, water-holding capacity, weight when wet, and adherence to surface microtopography (drapability). Both synthetic and natural geotextiles are available on the market, whereby synthetic materials tend to be more expensive and are not biodegradable. Therefore, even if they can stand aggressive chemical exposure (Dafalla and Obaid, 2013), they also cause soil pollution. Natural products are instead less costly, even if they only last for a few years (2-5) in the environment.

Geotextiles from organic materials are highly effective in controlling erosion and facilitating the establishment of vegetation. Due to their enhanced drapability, they can be more effective than synthetic materials in erosion reduction (Bhattacharyya et al., 2010). Further, they better maintain soil moisture conditions, thus favouring plant growth. Several studies in the literature have focused on assessing the effectiveness of biodegradable geotextiles for soil loss and runoff reduction. For instance, palm geotextiles have proved to reduce runoff coefficients and total soil loss in medium and steep slopes (Smets et al., 2007); cotton was showed to limit soil loss to negligible values in Mediterranean climatic conditions (Giménez-Morera et al., 2010); and hyacinth limited life geotextiles considerably reduced soil loss in laboratory conditions (Maneecharoen et al., 2013). Among biodegradable fibers, jute meets most of the technical requirements for geo-technical applications. The advantages of such a material are largely based on its high hygroscopic property, which offers high moisture regain and facilitates vegetation growth (Ghosh et al., 2014). However, jute accounts for only $1 \%$ of total geotextile use (Ghosh 
et al., 2014), and appropriate assessment studies on the technical capabilities of this fiber are still missing.

Recent research efforts on the use of geotextiles have focused on the erosion evaluation and the establishment of vegetation (Álvarez Mozos et al., 2014). Significant studies have also entailed the preparation and testing of advanced textiles including innovative materials. Geotextile assessments have been conducted both in laboratory (Smets et al., 2009) and field conditions (Jankauskas et al., 2012); however, field-based observations more reliably replicate erosion and runoff mechanisms (Smets et al., 2011b). More recently, experimental observations have been coupled with soil erosion models to improve the performance of predictive tools (Smets et al., 2011a).

Towards an improved comprehension of the interaction of biodegradable geotextiles and natural environments, further attempts should aim at extensive data collection and analysis in field conditions (Tauro et al., 2018). In this vein, here, we analysed the response of three biodegradable geotextiles in terms of soil loss to highly diverse natural and artificial precipitation conditions. We assessed the soil loss reduction effectiveness of jute net, jute mat, and wool mat in a steep outdoor artificial hillslope (more than $60 \%$ ). To provide a sound comparison, we investigated the response of the treatments with respect to a control bare soil plot and an uncovered vegetated area. In a set of experiments, the treatments were exposed to natural rainfall. In another set of tests, artificial rainfall provisioned from a rainfall simulator was used to irrigate the setup.

\section{Materials and methods}

\section{Biodegradable geotextiles}

Three soil conservation treatments were tested in an outdoor terrain parcel in the Azienda Agraria at the University of Tuscia, Viterbo, Italy. The treatments consisted in three commercially available biodegradable and water-permeable geotextile products manufactured by JutaTex (http://www.jutatex.com), namely: JutaNet 500 (JN), JutaTex 600 (JT), and LanaTex 750 (LT) (Figure 1). Their properties are reported in Table 1.

Jute geotextiles are widely adopted techniques for soil conservation due to their enhanced drapability and flexibility (Chen et al., 2011). JutaNet 500 rolls present a mesh of $30 \times 20 \mathrm{~mm}^{2}$ and a thickness of 3-4 mm. JutaTex 600 is composed of jute fibres and has larger thickness $(5 \mathrm{~mm})$ and mass per area $\left(600 \mathrm{gm}^{-2}\right)$.

LanaTex 750 is a fabric made from sheep wool. Wool mat geotextiles are widely adopted for soil conservation. In fact, they allow for minimal evaporation and provide thermal protection, thus facilitating seed germination (Broda et al., 2016). Also, during its slow degradation, wool supplies vegetation and microorganisms with nutrients (Queiroga et al., 2012). LanaTex 750 has a thickness of $6 \mathrm{~mm}$ and mass per area of $750 \mathrm{gm}^{-2}$.

\section{Experimental plots}

Field experiments were conducted on an ad hoc developed artificial hillslope at University of Tuscia, Viterbo, Italy (Figure 2). The hillslope has a conical shape, with a height of $2.1 \mathrm{~m}$, an apothem of $4 \mathrm{~m}$, and a base radius of $3.5 \mathrm{~m}$. Its circumference is of $21.4 \mathrm{~m}$ and it has a slope of $62 \%\left(32^{\circ}\right)$.

A characterisation of the hillslope soil was conducted based on five small collected samples. The soil average bulk density is 1.03 $\mathrm{gcm}^{-3}$, with a standard deviation (s.d.) of $0.04 \mathrm{gcm}^{-3}$. The soil presents an average organic content of $0.58 \%$ (s.d. $0.10 \%$ ) and, according to the United States Department of Agriculture soil taxonomy, it is a loam [44\% sand (s.d. $2.1 \%$ ), $35.6 \%$ silt (s.d. $2.4 \%$ ), and $20.4 \%$ clay (s.d. $2.2 \%$ )]. To evaluate the relative efficiency of the treatments, the hillslope was divided into five triangular plots, $8.5 \mathrm{~m}^{2}$ in area each. One control plot (bare ground, BG) was left uncovered and periodically mowed; one plot was uncovered, left undisturbed for a few weeks and vegetation was allowed to grow. In such vegetated plot (vegetated area), spontaneous herbaceous vegetation grew up to an average final height of $0.2 \mathrm{~m}$. Biodegradable geotextiles were laid and mechanically fixed to the ground on the remaining three plots.

The experiments were conducted from late September, 2016 to the end of November, 2016. During such an interval of time, the hillslope was exposed to both natural and artificial rainfall events. The geotextile materials were permanently installed on the plots during both sets of natural and artificial rainfall experiments. In the
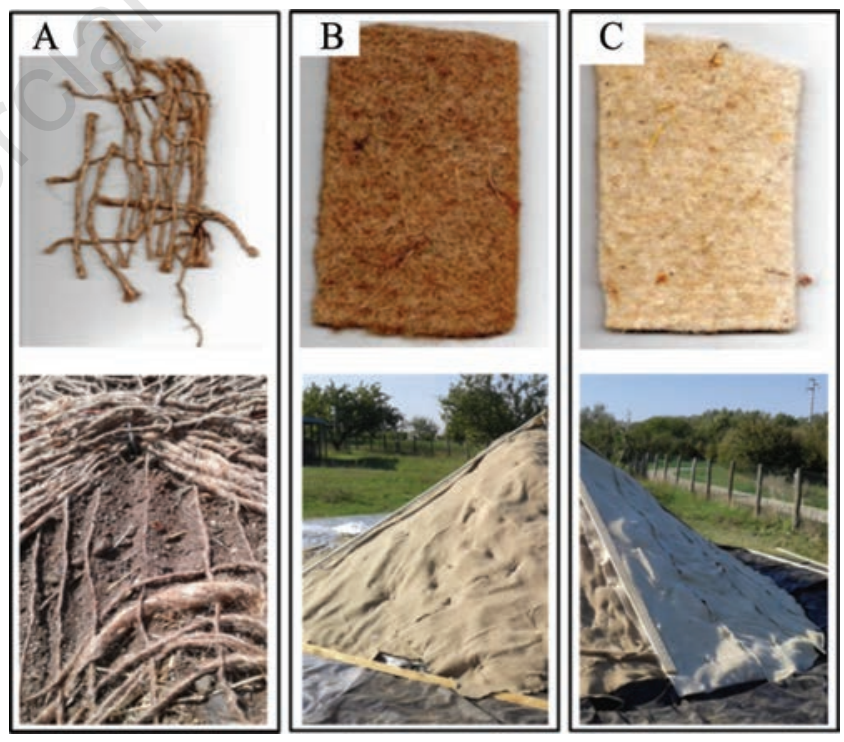

Figure 1. Biodegradable geotextiles used in the experiments: A) JutaNet 500; B) JutaTex 600; and C) LanaTex 750. Top pictures display geotextile samples and bottom images show the geotextiles installed onto the hillslope.

Table 1. Main properties of the tested biodegradable geotextiles.

\begin{tabular}{lccccc} 
Treatment & Roll sive $(\mathrm{m} \times \mathrm{m})$ & Thickness $(\mathrm{mm})$ & Mass per area $\left(\mathrm{gm}^{-2}\right)$ & Open area $(\%)$ & Tensile strength $\left(\mathrm{kNm}^{-1}\right)$ \\
JutaNet 500 & $1.22 \times 68$ & $3-4$ & 500 & 53 & $15-20$ \\
JutaTex 600 & $1-2 \times 30$ & 5 & 600 & - & - \\
\hline LanaTex 750 & - & 6 & 750 & - & - \\
\hline
\end{tabular}


aftermath of rainfall events, eroded material was collected and soil loss $\left(\mathrm{gm}^{-2}\right)$ computed. To facilitate the collection of eroded soil, a trench was digged around the hillslope and a waterproof layer (plastic sheet) installed as in Figure 2C. Wood panels were installed in the trench to prevent eroded material to mix at the base of the hillslope. The wet soil material eroded from each plot was manually collected with a sieve, stored in a metal container, and then weighed. Such wet material was oven dried at $65^{\circ} \mathrm{C}$ for $24 \mathrm{~h}$ and then the dry soil was again weighed.

Based on this weighed dry soil material, the soil loss rate was computed $\left(\mathrm{gm}^{-2} \mathrm{~h}^{-1}\right)$. Generally, the weighed amount of dry soil material was rather exiguous (less than $100 \mathrm{~g}$ ). However, special care was devoted to collect and handle experimental samples, thus guaranteeing a good measurement accuracy. To compare the efficacy of the treatments with respect to the control plot, the soil loss reduction effectiveness (SLRE, \%) was calculated (Álvarez Mozos et al., 2014) as:

$$
S L R E_{t}=\frac{\left(S L_{B G}-S L_{t}\right)}{S L_{B G}} \cdot 100
$$

where, $\mathrm{SL}_{t}$ and $\mathrm{SLBG}_{\mathrm{BG}}$ are the soil loss values of the treatment and the control, respectively.

Positive values of SLRE indicate that the treatment reduces soil loss as compared to the control.

\section{Rainfall events}

\section{Natural rainfall}

Experimental plots were exposed to five natural rainfall events (from 10 October, 2016 to 25 November, 2016) (Figure 3). Rainfall was monitored through a nearby facility [named the macro-rain gauge (Grimaldi et al., 2018)] located at a distance of $30 \mathrm{~m}$ from the hillslope. Therein, four SBS-500 Campbell Scientific standard rain gauges (collector area of $500 \mathrm{~cm}^{2}$ and tip sensitivity of $0.2 \mathrm{~mm}$ ) monitor rainfall at $5 \mathrm{~min}$ resolution. Rainfall was computed by averaging the measurements recorded by the four raingauges. Precipitation variables were calculated for each event. In particular, the accumulated precipitation $(\mathrm{P}, \mathrm{mm})$, rainfall duration $(\mathrm{D}, \mathrm{h})$, maximum intensity $\left(\mathrm{I}_{\max }, \mathrm{mmh}^{-1}\right)$, and average intensity $\left(\mathrm{I}_{\mathrm{av}}, \mathrm{mmh}^{-1}\right)$ are reported in Table 2 . The reported values of $\mathrm{I}_{\mathrm{av}}$ and $\mathrm{D}$ were computed based on non-zero rainfall amounts.

\section{Artificial rainfall}

To assess the response of the treatments in repeatable rainfall conditions, additional experimental tests were conducted using a rainfall simulator. The simulator was installed on the top of the hillslope (at $2.3 \mathrm{~m}$ from the ground) to uniformly irrigate the five plots. The system was designed and developed at the Polytechnic

Table 2. Main characteristics of the natural rainfall events. Accumulated precipitation (P), rainfall duration (D), maximum intensity $\left(I_{\max }\right)$, and average intensity $\left(I_{a v}\right)$ are reported.

\begin{tabular}{lccccc} 
Evvent & Date & $\begin{array}{c}\mathrm{P} \\
(\mathrm{mm})\end{array}$ & $\begin{array}{c}\mathrm{D} \\
\text { (h) }\end{array}$ & $\begin{array}{c}\mathrm{I}_{\max } \\
\left(\mathrm{mmh}^{-1}\right)\end{array}$ & $\begin{array}{c}\mathrm{I}_{\mathrm{av}} \\
\left(\mathrm{mmh}^{-1}\right)\end{array}$ \\
\hline 1 & Oct/10,2016 & 19.4 & 1.25 & 51.0 & 15.5 \\
2 & Oct/14, 2016 & 17.7 & 0.5 & 72.4 & 35.5 \\
\hline 3 & Oct/21, 2016 & 7.17 & 1.2 & 41.5 & 6.1 \\
4 & Nov/18, 2016 & 42.9 & 11.6 & 40.3 & 3.7 \\
\hline 5 & Nov/25, 2016 & 17 & 4.6 & 20.2 & 3.7 \\
\hline
\end{tabular}

of Milan based on the prototype by (Riley and Hancock, 1997). It comprises an aluminium tripod at whose uppermost end water is sprayed through three nozzles (Figure 2A). The nozzles (one big-
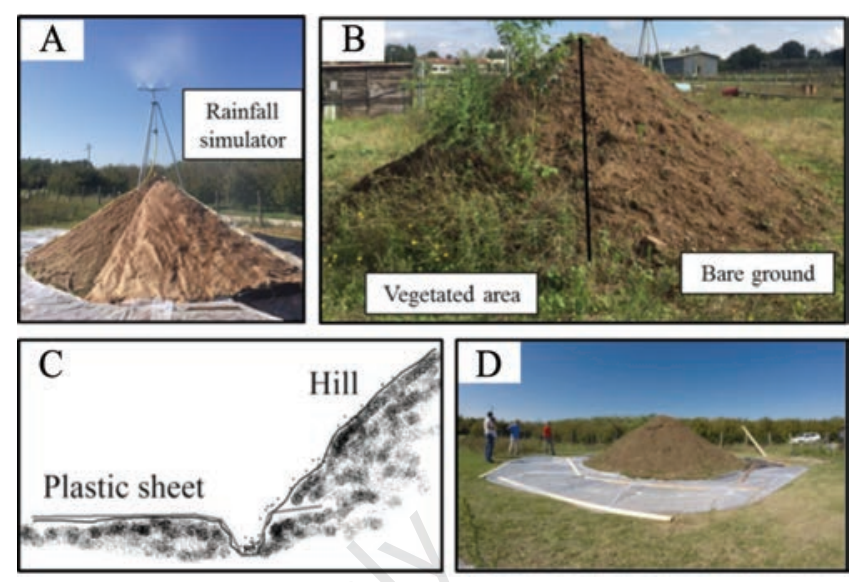

Figure 2. Experimental hillslope at University of Tuscia: A) two plots of the conical hillslope with treatments and rainfall simulator; B) two plots with vegetation and bare soil; C) sketch of the eroded material collection system; and $D$ ) view of the setup.
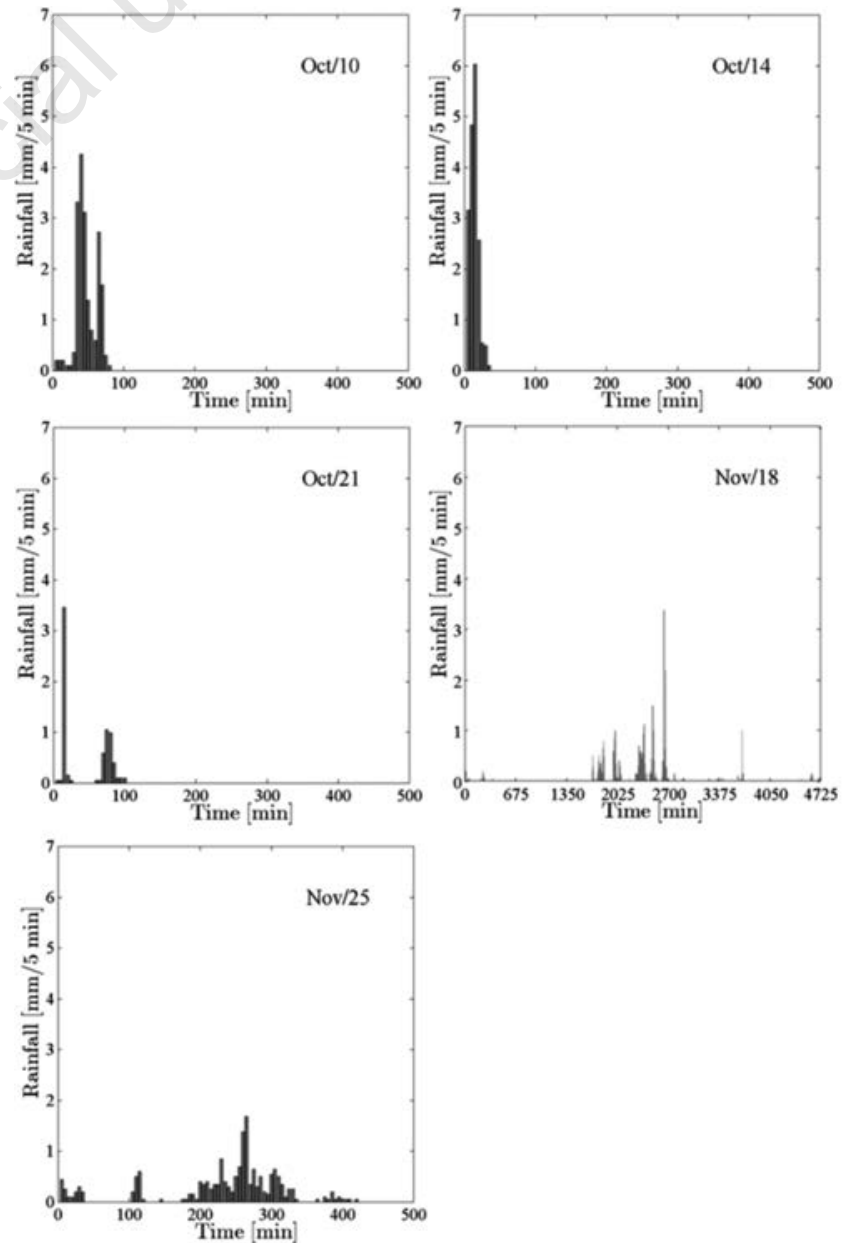

Figure 3. Natural precipitation events occurred from 10 October, 2016 to 25 November, 2016. 
ger HH7-M 3/4" and two smaller HH22-M 3/8) can be activated separately in order to control the rainfall intensity, which is regulated by using a pressure gauge.

The following configurations of the nozzles were preliminary tested in a separate outdoor space where wind effects are minimal: two smaller HH22-M 3/8 nozzles activated (C1); one small HH22M 3/8 and the bigger HH7-M 3/4 nozzle opened (C2); each nozzle opened (C3). To assess rainfall uniformity, micro raingauges were distributed on a $7 \times 7 \mathrm{~m}^{2}$ square grid at the reciprocal distance of 1 $\mathrm{m}$, while the simulator was placed at the centre of the square grid. The simulator pressure was varied from 0.4 to 1.8 bar. During each experiment, the simulator was activated at a constant pressure for a duration of 15-45 $\mathrm{min}$. At the end of each test, the rain gauges were weighed and rain intensity values computed for each node of the square grid. Four repetitions were conducted for each nozzle configuration. Average rainfall intensities over the square grid were related to the pressure and a coeffcient of uniformity over $60 \%$ was estimated. Similar rainfall simulators have also been used in (Tauro et al., 2012) and are permanently installed at the experimental hybrid plot Cape Fear (Petroselli and Tauro, 2017; Tauro et al., 2017).

A total of nine artificial rainfall experiments were executed on the hillslope, where each configuration $(\mathrm{C} 1, \mathrm{C} 2$, and $\mathrm{C} 3$ ) was repeated three times. The artificial configurations aimed at replicating moderate $(\mathrm{C} 1)$ to intense $(\mathrm{C} 3)$ precipitation events. Each test lasted for 30 minutes and a pressure of 1 bar was maintained throughout the experiments. Such a duration was sufficient to visually observe the onset of surface erosion on the experimental plots. In Table 3, the main characteristics of the artificial rainfall events are reported. In the following, soil loss rates from the treatments were averaged with respect to the rainfall replicates.

\section{Results}

\section{Influence of treatments on soil loss}

Based on the collected soil material, erosion rates were almost always higher in the control plot and in the vegetated area. The smallest erosion volumes were collected in the JutaNet treatment. As expected, soil loss rates from the treatments were generally lower than from the control, see Table 4 and the points below the 1:1 line in Figure 4. In fact, a minimum soil loss rate of 0.91 $\mathrm{gm}^{-2} \mathrm{~h}^{-1}$ was observed when the natural event at the lowest $\mathrm{I}_{\mathrm{av}}(3.7$ $\mathrm{mmh}^{-1}$ ) occurred. The maximum soil loss rate of the control (61.78 $\mathrm{gm}^{-2} \mathrm{~h}^{-1}$ ) occurred in the aftermath of a moderate natural event $\left(\mathrm{I}_{\mathrm{av}}=35.5 \mathrm{mmh}^{-1}\right)$, which presented the highest $\mathrm{I}_{\max }\left(72.4 \mathrm{mmh}^{-1}\right)$. This remarkable $I_{\max }$ occurred during the natural event on 14 October and resulted in the greatest soil loss in BG, JT, and LT observed during the experiments. This behaviour can be explained with the fact that the natural rainfall event on 14 October was preceded by the artificial rainfall experiments with configurations $\mathrm{C} 3$ and $\mathrm{C} 1$ as well as by the natural event on 10 October. Therefore, in the aftermath of these rather severe events, natural rainfall on 14 October may have triggered a threshold-effect that yielded considerable erosion.

The JutaTex 600 and JutaNet 500 treatment showed the lowest soil loss rates for all rainfall intensities. Also, the differences between treatments and control tended to be more evident at high soil loss rates. Generally, the vegetated area displayed lower soil loss rates than the control but higher than the treatments (with the exception of the second natural event, whereby a slightly higher soil loss rate was observed for LanaTex 750).

With regards to the treatments, all materials strongly abated soil loss; however, JutaNet 500 was the best performing geotextile.

Table 3. Main characteristics of the artificial rainfall events. Accumulated precipitation (P), rainfall duration (D), average $\left(I_{a v}\right)$, and maximum $\left(I_{\max }\right)$ intensities are reported. $C 1, C 2$, and C3 correspond to the following configurations of the rainfall simulator: two smaller $\mathrm{HH} 22-\mathrm{M}$ 3/8 nozzles activated (C1); one small HH22-M 3/8 and the bigger HH7-M 3/4 nozzle opened (C2); each nozzle opened (C3).

\begin{tabular}{lcccc} 
Configuration & $\mathbf{P}(\mathrm{mm})$ & $\mathrm{D}(\mathrm{h})$ & $\mathrm{I}_{\mathrm{av}}\left(\mathrm{mmh}^{-1}\right)$ & $\mathrm{I}_{\max }\left(\mathrm{mmh}^{-1}\right)$ \\
$\mathrm{C} 1$ & 17.5 & 0.5 & 35 & 35 \\
$\mathrm{C} 2$ & 27.5 & 0.5 & 55 & 55 \\
\hline $\mathrm{C} 3$ & 35.0 & 0.5 & 70 & 70 \\
\hline
\end{tabular}

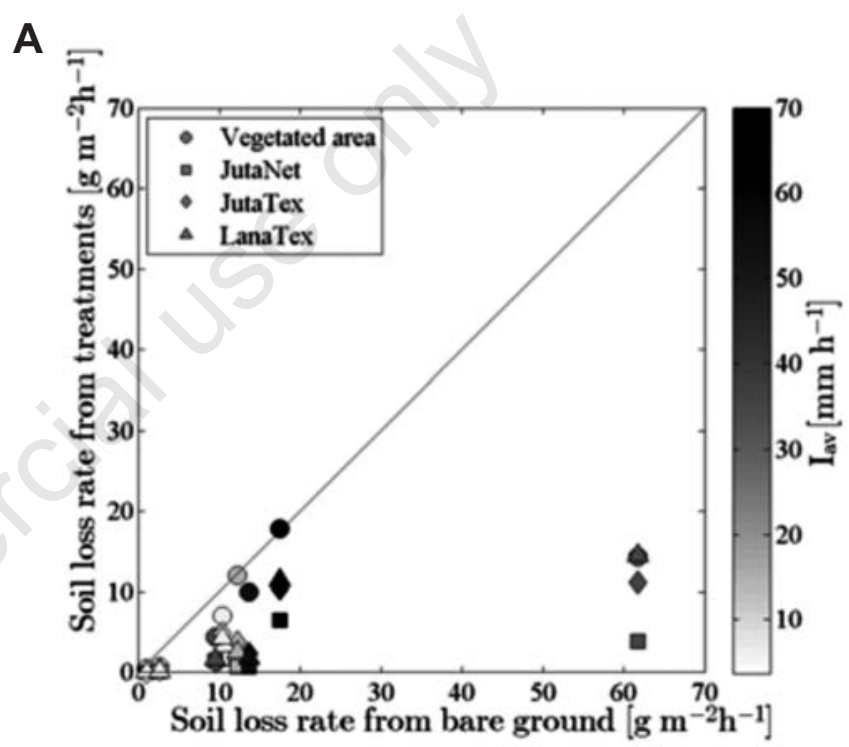

B

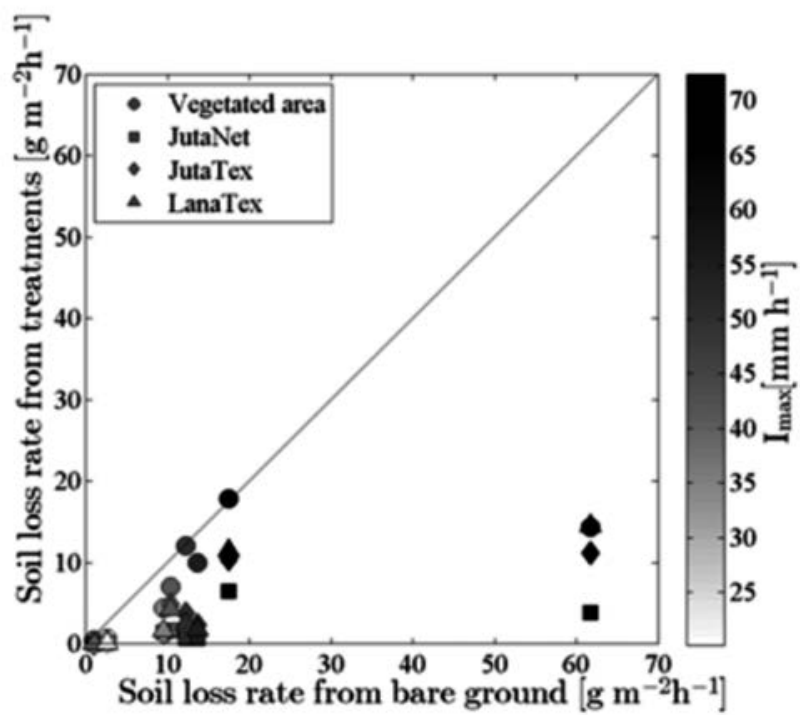

Figure 4. Soil loss rate from treatments against those from control. The 1:1 line is plotted as a reference. The colour bars indicate: A) $I_{a v}$; and B) $I_{\max }$ of the rainfall events. 
Such a behaviour was not expected since JutaNet 500 features the lowest soil cover percentage with respect to the alternative treatments. Most probably, thanks to its mesh, JutaNet 500 perfectly adheres to the soil, thus significantly decreasing runoff surface velocity. On the other hand, JutaTex 600 and LanaTex 750 effectively reduce the impact of raindrops but, due to their high permeability, do not sensibly reduce surface runoff formation.

\section{Dependence of the treatment responses on rainfall}

In Figure 4, soil loss rates for all treatments are plotted against the control. Further, the colour bar illustrates the average and maximum rainfall intensity of the event, respectively. Soil loss rates tend to be more closely related to $I_{\max }$ than $I_{a v}$.

To further investigate the relation between treatment response and precipitation, in Figures 5 and 6, soil loss rates from each treatment are normalised by the soil loss rate of the bare ground and plotted against $I_{a v}$ and $I_{\max }$, respectively. Therein, we compare the responses of the geotextiles to both natural and artificial events and, therefore, neglect the influence of the temporal distribution of rainfall intensity on soil loss. According to this simplifying assumption, soil loss only depends on the cumulated amount of rainfall water. While this hypothesis was supported by the experimental evidence that soil erosion was not observed in the absence of precipitation, we acknowledge that the sequence of rainfall events may play a role in long-term plot erosion mechanisms. For instance, similar to Figure 4, data relative to the highest $I_{\max }(72.4$ $\mathrm{mmh}^{-1}$ ) did not align with the expected behaviour (probably due to a threshold-effect) and generally led to low coefficient of determination values. Pearson's correlation coeffcients ( $\rho$, an $*$ indicates if significant at $\mathrm{P}<0.05$ ) between the soil loss rates are reported in Table 5 with respect to $I_{a v}, I_{\max }$, and D. Interestingly, $\rho$ values are higher in case of $\mathrm{I}_{\max }$, and the relations between soil loss rate and rainfall intensity are statistically significant. The relation between soil loss and $\mathrm{I}_{\mathrm{av}}$ was stronger in the vegetated area and JutaNet 500 . On the other hand, the relation with $\mathrm{I}_{\max }$ was similar in the control and treatments. JutaNet 500 generally exhibited higher protection (and less soil loss) as precipitation intensity increased. As reported in Table 5 and in agreement with (Álvarez Mozos et al., 2014), soil loss is negatively correlated with rainfall duration. In fact, longer rainfall events are typically characterised by lower intensities. This supports the fact that $I_{\max }$ may be a meaningful parameter to estimate the severity of rainfall events in terms of soil loss.

\section{Geotextile treatment effectiveness}

In Table 6, the SLREs of the treatments are reported. On average, the vegetated area has an SLRE of 39.6\%, which is lower than
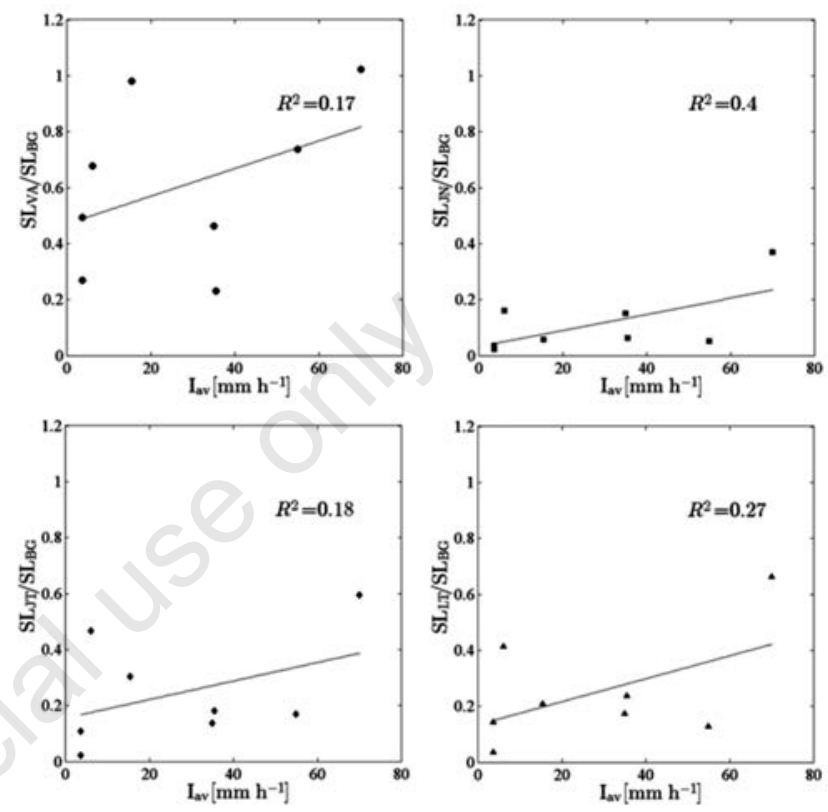

Figure 5. $I_{a v}$ against soil loss (SL) rate for the control and all treatments. Data points are fitted with a linear model. Coefficients of determination values $\left(\mathbf{R}^{2}\right)$ are reported.

Table 4. Soil loss rates for each treatment and rainfall event. For artificial rainfall configurations, we report minimum (left number) and maximum (right number) soil loss rate values.

\begin{tabular}{|c|c|c|c|c|c|}
\hline Event/configuration & $\mathrm{BG}\left(\mathrm{gm}^{-2} \mathrm{~h}^{-1}\right)$ & VA $\left(\mathrm{gm}^{-2} \mathrm{~h}^{-1}\right)$ & JN $\left(g^{-2} h^{-1}\right)$ & JT $\left(g^{-2} h^{-1}\right)$ & LT $\left(\mathrm{gm}^{-2} \mathrm{~h}^{-1}\right)$ \\
\hline 1 & 12.22 & 11.99 & 0.68 & 3.72 & 2.53 \\
\hline 2 & 61.78 & 14.31 & 3.81 & 11.16 & 14.57 \\
\hline 3 & 10.33 & 7.00 & 1.65 & 4.82 & 4.27 \\
\hline 4 & 0.91 & 0.45 & 0.02 & 0.02 & 0.13 \\
\hline 5 & 2.60 & 0.70 & 0.09 & 0.28 & 0.09 \\
\hline $\mathrm{Cl}$ & $2.25-17.20$ & $1.31-8.25$ & $0.12-2.42$ & $0.37-2.58$ & $0.28-3.85$ \\
\hline $\mathrm{C} 2$ & $8.30-16.83$ & $5.81-15.64$ & $0.08-1.24$ & $1.39-4.00$ & $0.43-3.55$ \\
\hline C3 & $8.92-28.16$ & $9.88-33.06$ & $0.72-14.49$ & $9.68-11.72$ & $3.43-26.54$ \\
\hline
\end{tabular}

BG, bare ground; VA, vegetated area; JN, JutaNet 500; JT, JutaTex 600; LT, LanaTex 750.

Table 5. Pearson's correlation coefficients for the relations between soil loss rate and $I_{a v}, I_{\max }$, and D.

\begin{tabular}{lcccccc} 
& BG & VA & JN & JT & LT \\
$\mathrm{I}_{\mathrm{av}}$ & 0.34 & 0.74 & 0.72 & 0.56 & 0.54 \\
$\mathrm{I}_{\max }$ & 0.73 & 0.91 & 0.76 & 0.87 & 0.84 \\
\hline $\mathrm{D}$ & -0.44 & -0.68 & -0.47 & -0.53 & -0.46 \\
\hline
\end{tabular}

BG, bare ground; VA, vegetated area; JN, JutaNet 500; JT, JutaTex 600; LT, LanaTex 750. 
the treatments' values. JutaNet 500 showed the highest SLRE (on average equal to $88.8 \%$ ), followed by JutaTex $600(75.4 \%)$ and LanaTex $(75.2 \%)$. Even if clear relations between SLRE and $\mathrm{I}_{\mathrm{av}}$ or Imax were not found, SLRE was observed to decrease with increasing rainfall intensity in the vegetated area. This behaviour was less evident in the treatments.

\section{Discussion}

Experimental findings confirmed that biodegradable geotextiles are efficient techniques for soil conservation. They offer high SLRE in case of moderately high $\mathrm{I}_{\max }$ and soil loss is reduced with increasing rainfall duration. Their effectiveness is comparable to artificial materials tested at lower slopes (Chen et al., 2011). The selected materials also presented enhanced effectiveness with respect to alternative natural textiles, see, for instance Smets et al.
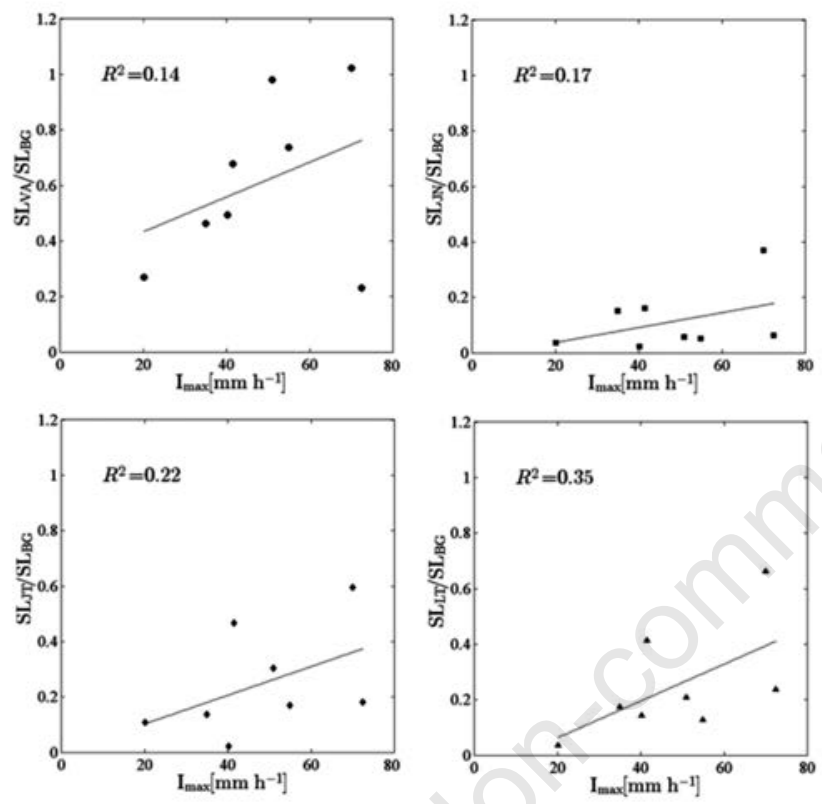

Figure 6. $I_{\max }$ against soil loss (SL) rate for the control and all treatments. Data points are fitted with a linear model. Coefficients of determination values $\left(\mathbf{R}^{2}\right)$ are reported.

Table 6. Soil loss reduction effectiveness for the treatments. Values relative to artificial rainfall configurations were averaged with respect to the replicates.

\begin{tabular}{lcccc}
\hline Event/configuration & VA $\%$ & JN \% & JT \% & LT \% \\
1 & 1.9 & 94.4 & 69.6 & 79.3 \\
2 & 76.8 & 93.8 & 81.9 & 76.4 \\
\hline 3 & 32.2 & 84.0 & 53.3 & 58.7 \\
4 & 50.5 & 97.8 & 97.8 & 85.7 \\
\hline 5 & 73.1 & 96.5 & 89.2 & 96.5 \\
C1 & 53.8 & 84.9 & 86.2 & 82.6 \\
\hline C2 & 26.4 & 94.9 & 83.1 & 87.3 \\
C3 & -2.2 & 63.1 & 40.4 & 33.8 \\
\hline
\end{tabular}

VA, vegetated area; JN, JutaNet 500; JT, JutaTex 600; LT, LanaTex 750.
(2009, 2011b). This behaviour may be also attributed to the experimental conditions (including natural rainfall), which did not favour concentrated erosion processes. The treatments generally displayed similar responses in case of natural and artificial conditions. Although the artificial $\mathrm{C} 3$ configuration presents a high $\mathrm{I}_{\mathrm{av}}$, geotextiles' effectiveness was acceptable and in all treatments higher than $30 \%$.

Even if clear relationships could not be established, the effectiveness of all treatments was reduced as rainfall intensity increased. Similar findings were showed in Liu et al. (2016), where geotextiles installed on a slope of $70 \%$ were tested in moderate to high rainfall intensities. Also, in Kalibová et al. (2017), the effectiveness of geotextiles was found to decrease for higher rainfall intensities, even if, in case of jute net, the SLRE increased with rainfall duration for a rainfall intensity of $90.5 \mathrm{mmh}^{-1}$. According to our findings, soil loss rate was highly correlated with $\mathrm{I}_{\max }$ rather than $\mathrm{I}_{\mathrm{av}}$. This result may be related to splash erosion effects, which may have been substantial at the plot. We point out that the temporal distribution of rainfall intensity may also play a key role on soil erosion. Even if such phenomenon was not considered in this study, some results highlighted a possible threshold-effect related to the temporal proximity of rainfall events and will be investigated through dedicated experiments.

JutaNet 500 proved the best performing biodegradable geotextile among the selected materials. Given the rather steep plot slopes (more than 60\%) and the moderately high $\mathrm{I}_{\max }$ values, this result is remarkable. In similar studies, the erosion rate from jute net was found to be highly controlled by the plot slope, with high effectiveness values (99\%) in case of slopes less than $30^{\circ}$ (Kalibová et al., 2016), and with extremely low efficiency in case of steep slope $\left(60^{\circ}\right)$ (Álvarez Mozos et al., 2014). However, numerous studies have confirmed that jute net typically results in positive soil loss reduction compared to the control in both field and laboratory conditions (Mitchell et al., 2003; Álvarez Mozos et al., 2014). In a few cases (Kalibová and et al., 2017), jute net was found to increase soil loss, rather than eliminate it.

In Mitchell et al. (2003), the higher SLRE of jute net with respect to jute mat is attributed to the fact that such a material is highly efficient at reducing infiltration during rainfall events. However, in case of long rainfall events, mats saturate, thus facilitating infiltration and soil erosion. Similarly, in this work, the jute net may have formed a system of micro-dams that trapped fine sediments and decreased splash erosion. Further, both JutaNet 500 and JutaTex 600 resulted in higher SLRE values than LanaTex. This can be explained with the fact that when exposed to rainfall, jute geotextiles become wet and increase drapability, thus enhancing their runoff and erosion control capability (Mitchell et al., 2003).

\section{Conclusions}

In a world of change, soil loss and earth instability posit urgent challenges for human activities. Biodegradable geotextiles have a great potential to mitigate soil loss, guarantee soil stability, and foster vegetation growth in territories at risk.

In this work, we studied the response of three jute and woolbased geotextiles to natural and artificial precipitation conditions in an ad hoc developed outdoor slope. The experimental setup featured quite adverse settings, including a steep slope (more than $60 \%$ ) and diverse precipitation events (average rainfall intensity from $3.7 \mathrm{mmh}^{-1}$ to $70 \mathrm{mmh}^{-1}$ and event duration from $0.5 \mathrm{~h}$ to 11.6 h). Based on our findings, all materials efficiently decreased soil 
loss, with reductions up to $98 \%$, as compared to bare ground and a naturally vegetated area. On average, JutaNet 500 outperformed JutaTex 600 and LanaTex 750, since its structure favoured the establishment of micro-dams in the hillslope. Soil loss from all treatments significantly correlated with the maximum intensity of the rainfall events. This dependence, to the best of our knowledge undocumented in the literature, could be further investigated to offer a better comprehension of the response of soil conservation techniques in natural ecosystems.

\section{References}

Álvarez Mozos J., Abad E., Giménez R., Campo M. A., Goñi M., Arive M., Casalí J., Déz J., Diego I. 2014. Evaluation of erosion control geotextiles on steep slopes. Part 1: Effects on runoff and soil loss. Catena 118:168-78.

Bhattacharyya R., Smets T., Fullen M.A., Poesen J., Booth C.A. 2010. Effectiveness of geotextiles in reducing runoff and soil loss: a synthesis. Catena 81:184-95.

Bresci E., Preti F. 2010. An historical survey on the evolution of some forestwatershed management techniques (Part II: stream channel works). J. Agr. Eng. 41:13-22.

Broda J., Przybyło S., Kobiela-Mendrek K., Biniaś D., Rom M., Grzybowska-Pietras J., Laszczak R. 2016. Biodegradation of sheep wool geotextiles. Int. Biodeter. Biodeg. 115:31-8.

Chen S.C., Chang K.T., Wang S.H., Lin J.Y. 2011. The efficiency of artificial materials used for erosion control on steep slopes. Environ. Earth Sci. 62:197-206.

Dafalla M., Obaid A. 2013. The role of polypropylene fibers and polypropylene geotextile in erosion control. In: IACGE2013: Challenges and Recent Advances in Geotechnical and Seismic Research and Practices, Chengdu, China, October 25-27, ASCE.

Evette A., Labonne S., Rey F., Liebault F., Jancke O., Girel J. 2009. History of bioengineering techniques for erosion control in rivers in Western Europe. Environ. Manage. 43:972-84.

Ghosh S. K., Bhattacharyya R., Mondal M.M. 2014. A review on jute geotextile - Part 1. Int. J. Res. Eng. Technol. 3:378-86.

Giménez-Morera A., Ruiz Sinoga J.D., Cerdà A. 2010. The impact of cotton geotextiles on soil and water losses from Mediterranean rainfed agricultural land. Land Degrad. Dev. 21:210-7.

Grimaldi S., Petroselli A., Baldini L., Gorgucci E. 2018. Description and preliminary results of a 100 square meter rain gauge. J. Hydrol. 556:827-34.

Guerra A.J.T., Bezerra J.F.R., Fullen M.A., Mendonca J.K.S., Jorge M.C.O. 2015. The e $\square$ ects of biological geotextiles on gully stabilisation in São Luís, Brazil. Nat. Hazards 75:2625-36.

Jankauskas B., Jankauskiene G., Fullen M.A. 2012. Soil conservation on road embankments using palm-mat geotextiles: field studies in Lithuania. Soil Use Manage. 28:266-75.

John N.W.M. 1987. Geotextiles. Chapman \& Hall, New York, NY, USA.

Kalibová J., Petrû L., Jačka J. 2017. Impact of rainfall intensity on the hydrological performance of erosion control geotextiles. Environ. Earth Sci. 76:429.

Kalibová J., Jačka J. Petrû L. 2016. The effectiveness of jute and coir blankets for erosion control in di $\square$ erent field and laboratory conditions. Solid Earth 7:469-79.
Liu H., Wang J., Zhang K., Kong Y. 2016. E $\square$ ectiveness of geotextiles for road slope protection under simulated rainfall. Environ. Earth Sci. 75:1198.

Luo H., Zhao T., Dong M., Gao J., Peng X., Guo Y., Wang Z., Liang C. 2013. Field studies on the effects of three geotextiles on runoff and erosion of road slope in Beijing, China. Catena 109:150-6.

Maneecharoen J., Htwe W., Bergado D.T., Baral P. 2013. Ecological erosion control by limited life geotextiles (LLGs) as well as with Vetiver and Ruzi grasses. Ind. Geotech. J. 43:388-406.

Mitchell D.J., Barton A.P., Fullen M.A., Hocking T.J., Zhi W.B., Yi Z. 2003. Field studies of the effects of jute geotextiles on runoff and erosion in Shropshire, UK. Soil Use Manage. 19:182-4.

Petroselli A. Tauro F. 2017. Cape Fear: monitoring basic hydrological processes in an outdoor hillslope plot. Environ. Monit. Assess. 189:132.

Queiroga A.C., Pintado M.E., Malcata F.X. 2012. Potential use of wool-associated bacillus species for biodegradation of keratinous materials. Int. Biodeter. Biodegr. 70:60-5.

Riley S.J., Hancock F. 1997. A rainfall simulator for hydrologic and erosion experiments on mines, with an example of its applications at Ranger Uranium Mine, Northern Territory, Australia. Aus. Inst. Min. Metall. Proc. 1:3-8.

Smets T., Poesen J., Fullen M.A., Booth C.A. 2007. Effectiveness of palm and simulated geotextiles in reducing run-off and inter-rill erosion on medium and steep slopes. Soil Use Manage. 23:306-16.

Smets T., Poesen J., Langhans C., Knapen A., Fullen M.A. 2009. Concentrated flow erosion rates reduced through biological geotextiles. Earth Surf. Proc. Land. 34:493-502.

Smets T., Borselli L., Poesen J., Torri D. 2011a. Evaluation of the EUROSEM model for predicting the effects of erosion-control blankets on runoff and interrill soil erosion by water. Geotext. Geomembranes 29:285-97.

Smets T., Poesen J., Bhattacharyya R., Fullen M.A., Subedi M., Booth C.A., Kertész A., Szalai Z., Toth A., Jankauskas B., Jankauskiene G., Guerra A., Bezerra J.F.R., Yi Z., Panomtaranichagul M., Bühmann C., Paterson D.G. 2011b. Evaluation of biological geotextiles for reducing runo- and soil loss under various environmental conditions using laboratory and field plot data. Land Degrad. Dev. 22:480-94.

Tauro F., Grimaldi S., Petroselli A., Rulli M.C., Porfiri M. 2012. Fluorescent particle tracers in surface hydrology: a proof of concept in a semi-natural hillslope. Hydrol. Earth Syst. Sci. 16:2973-83.

Tauro F., Petroselli A., Fiori A., Romano N., Rulli M.C., Porfiri M., Palladino M., Grimaldi S. 2017. "Cape Fear" - a hybrid hillslope plot for monitoring hydrological processes. Hydrology 4:35.

Tauro F., Selker J., van de Giesen N., Abrate T., Uijlenhoet R., Porfiri M., Manfreda S., Caylor K., Moramarco T., Benveniste J., Ciraolo G., Estes L., Domeneghetti A., Perks M.T., Corbari C., Rabiei E., Ravazzani G., Bogena H, Harfouche A., Brocca L., Maltese A., Wickert A., Tarpanelli A., Good S., Lopez Alcala J.M., Petroselli A., Cudennec C., Blume T., Hut R., Grimaldi S. 2018. Measurements and observations in the XXI century (MOXXI): innovation and multidisciplinarity to sense the hydrological cycle. Hydrol. Sci. J. 63:169-96.

Vishnudas S., Savenije H.H.G., VanderZaag P., Anil K.R. 2012. Coir geotextile for slope stabilisation and cultivation - A case study in a highland region of Kerala, South India. Phys. Chem. Earth Pt. A/B/C, 47:135-8. 